\title{
EFEITO PLACEBO - IMPLICAÇŌES PARA A ASSISTÊNCIA E O ENSINO DE ENFERMAGEM
}

\author{
Miriam Aparecida Barbosa Merighi* \\ Ivete Ollita \\ Thelma Ribeiro Garcia
}

MERIGHI, M. A. B.; OLLITA, I.; GARCIA, T. R. Efeito placebo: implicações para a assistência e o ensino de enfermagem. Rev. Esc. Enf. USP, São Paulo 23(2): -, ago. 1989.

As autoras fazem uma revisão bibliografica sobre o placebo e o efeito placebo, enfocando sua conceituação, histórico, tipos, ação, indicaçóes e caractertsticas da placebo reator, para fundamentar as implicaçöes do seu uso e efeitos para o ensino e a assistência de enfermagem.

UNITERMOS. Assistência de enfermagem. Placebos.

\section{INTRODUÇÃO}

O uso de medicamentos como agentes terapêuticos é conhecido através da Historia. Fazendo-se um estudo retrospectivo da Medicina podemos observar que durante muito tempo, o uso de drogas, a religiäo e a criação e deuses confundiamse com a figura de sacerdotes, feiticeiros, bruxas e pajés.

A liderança social destes indivíduos estava baseada e reforçada no ocultismo do prognóstico; no fato de a maioria das doenças serem provocadas por agentes inviáveis (que se confundiam com os maus espíritos); na necessidade de apoio psicológico do indivíduo doente; no conhecimento e manuseio de plantas medicinais, tóxicas e alucinógenas e em fatores psicológicos, tais como fenômenos de sugestão, mecio e desejo de cura. Aliava-se, assim, a administraçāo de drogas a verdadeiros rituais que, de uma maneira ou de outra, vinham satisfazer a necessidade do homem de buscar auxilio no seu semelhante. Tudo isso conferia aos remédios e a quem os administrava um poder místico, ZANINI et alii ${ }^{20}$.

\footnotetext{
* Enfermeira, Mestre em Enfermagem. Professor Assistente do Departamento de Enfermagem MaternoInfantil e Psiquiátrica da Escola de Enfermagem da USP

** Enfermeira. Mestre em Enfermagem. Chefe do Serviço de Enfermagem do Hospital Público Municipal

*** Enfermeira. Mestre em Enfermagem
}

Rev. Esc. Enf. USP, Sāo Paulo, 23(2):83-93, abr. 1989 
Ao conjunto de fatores que influenciam a ação dos medicamentos, além de sua ação farmacológica, deu-se o nome de efeito placebo e, segundo ZANINI \& $\mathrm{OGA}^{21}$ "pode-se admitir que, até o princípio do século $\mathrm{XX}$, a maioria dos benefícios atingidos com o uso de remédios era fundamentalmente decorrente do uso do placebo".

O emprego do placebo tem suscitado inúmeras controvérsias e dado origem a muitas pesquisas experimentais, além de muitos mitos terem sido criados ao seu redor. Para nós, portanto, enquanto enfermeiros responsáveis pela administração de medicamentos aos pacientes, o estudo do efeito placebo é fundamental, importando conhecer o que é o placebo, o que representa para a terapêutica, que pessoas reagem à sua administração e quais as implicações do seu emprego para a enfermagem.

É o que propomos a apresentar neste trabalho.

\section{1 - O EFEITO PLACEBO - ASPECTOS RELEVANTES PARA A ENFERMAGEM}

\section{1 - Definição de Placebo}

A palavra placebo foi introduzida pelos autores anglo-saxōes para designar uma terapêutica fictícia ou em branco VELASQUEZ ${ }^{16}$. Segundo SHAPIRO ${ }^{13}$, ela corresponde à primeira pessoa do singular do futuro do indicativo do verbo latino agradar, equivalendo à frase "eu agradarei".

Todas as definiçōes encontradas para o termo, com pequenas variaçōes são similares. Assim:

- O Hooper's Medical Dictionary, em 1811, definiu placebo como "um epíteto dado a alguma medicaçāo adotada mais para agradar do que para beneficiar o paciente" (SHAPIRO ${ }^{13}$ ).

- O Dorland Medical Dictionary, em 1951, definiu como "uma substância ou preparação inativa, outrora administrada para agradar ou gratificar um paciente, agora também usada em estudos controlados para determinar a eficácia de substâncias medicinais"'(SHAPIRO ${ }^{13}$ ).

- Para COLEMAN", "a palavra placebo é normalmente usada para designar um medicamento que não exerce nenhum efeito físico sobre o paciente, que nāo traz nenhum benefício físico a ele mas que deve ter um efeito psicológico definido e importante".

- TROUNCE" 15 define-o como "uma substância sem ação farmacológica, mas que é usada para produzir um efeito terapêutico".

- COUTINHO ${ }^{6}$ define placebo como "termo latino com que se designa qualquer substância ou preparo inativo dado a um doente, nāo com o fim de 
exercer qualquer ação definida, mas porque o paciente não sossega enquanto se lhe não fizer qualquer tratamento".

\section{2 - Tipos de placebo}

Segundo SHAPIRO"13, "o tipo mais largamente conhecido é o placebo puro - uma substância inerte tal como lactose, comprimidos de açúcar ou amido, água destilada ou solução salina isotônica que fisiológica, biológica e organicamente são inativas. Outro tipo mais sutil e quase sempre irreconhecível é o impuro ou placebo adulterado que contém algum ingrediente ativo, mas que não exerce nenhum efeito sobre a doença do paciente. Ele deve conter uma substância certamente ativa, mas é dado em circuntâncias inapropriadas ou em dosagens inadequadas".

CARVALHO NETO ${ }^{4}$ classifica os placebos em ativos e inertes. Os inertes correspondendo aos "placebos puros" citados por SHAPIRO ${ }^{13}$ e os ativos aos tipos impuros. Como exemplo destes últimos, cita os analgésicos utilizados em doses subterapêticas e a vitamina B 12 para tratamento "revigorante" em pacientes sem anemia perniciosa. $O$ autor inclui, também, no grupo dos placebos ativos, substâncias farmacologicamente ativas, prescritas em doses certas, porém para indicaçōes erradas.

Em relação a procedimentos que possam exercer efeito placeboVOGEL et alii ${ }^{17}$ afirmam que "estudos antropológicos e sociológicos têm sugerido que um significante efeito placebo pode acompanhar uma variedade de procedimentos médicos que não têm valor terapêutico específico. Desta forma, torna-se difícil determinar a verdadeira eficácia terapêutica de procedimentos cirúrgicos tais como a vagotomia e piloroplastia em úlcera péptica".

A aparência e a forma de apresentação da droga placebo são importantes. Em seu trabalho, COLEMAN ${ }^{5}$ cita Routon, o qual afirmou que, para propósitos médicos, os placebos devem ser preferencialmente vermelhos, amarelos, ou marrons, de sabor amargo e nem muito grandes nem muito pequenos. As cápsulas parecem mais efetivas que os comprimidos e, para alguns pacientes, a forma parenteral funciona melhor.

Lasagna, citado por GOSHEN ${ }^{8}$, sugeriu que, para ser comercialmente bem sucedido, um placebo deve ser, primeiro, essencialmente atóxico; segundo, nāo deve haver nenhuma droga evidente para comparação e terceiro, ele deve ser supostamente útil para algo que seja de difícil avaliação ou que tenha um alto índice de remissão expontânea. Segundo o autor, há duas classes de droga que preenchem estes critérios: os medicamentos para resfriados comuns e as assim chamadas, drogas tranquiilizantes.

\section{3 - Histórico e definição de efeito placebo.}

$\mathrm{O}$ efeito placebo tem sido responsabilizado pela eficácia de grande número 
de terapias através da História da Medicina. Somente nos últimos 30 anos, entretanto, coincidindo com a introdução de medicações de comprovada eficácia biológica é que os efeitos do tratamento placebo têm sido estudados sistematicamente (GOODWIN et $\mathrm{alii}^{7}$ ).

Segundo COLEMAN ${ }^{5}$, o efeito placebo foi registrado pela primeira vez em 1946 por um médico chamado Vellinek, o qual descobriu que de 199 pacientes que se queixavam de cefaléia, 120 obtiveram alívio tomando comprimido que não continha ingrediente ativo.

Entretanto, para LOWINGER \& DOBIE ${ }^{10}$, o interesse atual pelo placebo é devido em grande parte a BEECHER ${ }^{2}$ que teve a inspiração para seus estudos enquanto trabalhava em Anzio, durante a II Guerra Mundial. Ele observou que apenas $25 \%$ dos soldados com graves ferimentos de guerra necessitavam de morfina para alívio da dor. Em comparação, $80 \%$ dos civis com ferida pós-operatória soliitavam medicação analgésica. No caso dos civis, a cirurgia representava problemas de ordem sócio-econômica ou familiar, enquanto que para os soldados os ferimentos representavam a passagem para a relativa segurança do hospital e, logo após, o retorno para seus lares.

Quanto ao que significa efeito placebo, SHAPIRO ${ }^{13}$ o descreveu como "o efeito psicológico, fisiológico ou psicoficiológico de alguma medicação ou procedimento administrado ou realizado com intentos terapêuticos, o qual é independente de, ou minimamente relacionado com os efeitos farmacológicos da medicação ou com os efeitos específicos do procedimento, e que opera através de um mecanismo psicológico".

CARVALHO NETO 4 o define como "respostas que não podem ser explicadas como devidas à ação farmacodinâmica da droga administrada".

\section{4 - Quem é o placebo reator.}

Nenhum retrato claro do "típico placebo reator" emerge da literatura sobre o assunto. Segundo Rickles, citado por ZANINI et alii20, "os pacientes respondem melhor ao placebo quando são jovens, portadores de doenças agudas, sem experiência medicamentosa prévia, possuidores de QI baixo, reduzido nível educacional e sócio-econômico e desprovidos de ansiedade severa ou moderada".

GOODWIN et alii ${ }^{7}$ fazem referência ao trabalho desenvolvido por Moertel et alii, os quais categorizaram os placebos reatores como auto-suficientes, de alto-nível educacional, com pesadas responsabilidades, desacostumados com a dependência que as doenças mutiladoras acarretam.

Para SHAPIRO ${ }^{13}$, não existem características de personalidade que possam ser relacionadas de forma consistente com o efeito placebo mas o autor acredita que há uma tendência dos placebos reatores para reeatar menos sintomas somáticos do que o fazem os não-reatores. 
Em concordância com isto, Lasagna et alii, também citados por GOODWIN et alii ${ }^{7}$, encontraram em seus trabalhos resultados que mostram que os placebos reatores tendem a solicitar medicaçōes menos freqüentemente e, além disso, a ser mais cooperadores com a equipe de enfermagem do que os não-reatores.

PERRY \& HEIDRICH ${ }^{12}$ acreditam que a forma como o placebo é administrado e por quem, influencia mais o seu efeito do que qualquer característica do paciente. Citam como exemplo disso o estudo realizado por D. Wheatley, cujos resultados indicaram que "a fé que o médico tem na droga que está prescrevendo e a maneira como esta fé é transmitida ao paciente exercem uma influência marcante no efeito da droga".

Segundo WALIKE \& MEYER ${ }^{18}$, "o comportamento da enfermagem exerce um papel significante nas reaçōes placebo, não somente durante a administração ocasional de uma substância placebo mas, também, durante as atividades e interação com a família, quando os enfermeiros podem, por si mesmos, exercer um cfeito placebo".

Os placebos reatores não são, entāo, aqueles pacientes mais lastimosos os aborrecidos; eles não sāo tipicamente homens ou mulheres novos ou velhos, ou diferentes em inteligência. Pessoas mais "emocionais" e menos "racionais" não são mais suscetíveis a placebo, da mesma forma que uma personalidade tipicamente histérica não predispōe à reação placebo. Ao invés, toda sorte de pessoas, em uma variedade de ambientes, com muitos tipos de afecçōes já responderam aos placebos. Dadas as circunstâncias próprias, qualquer um pode ser um placebo reator.

\section{5 - Açäo dos placebos}

Um mito corrente em relação ao uso dos placebos é que eles agem sobre a mente das pessoas e não sobre o corpo.

BEECHER" afirma que "não se deve supor que a ação dos placebos é limitada a reaçōes psicológicas. Muitos exemplos podem ser dados de modificaçōes fisiológicas produzidas por placebos".

PERRY \& HEIDRICH ${ }^{12}$ citam como exemplos de reaçōes fisiológicas que os placebos podem causar: constrição das pupilas, aumento da pressão sangüinea, modificaçōes do ritmos respiratório e cardíaco, modificaçōes na temperatura corporal. Além disso, eles podem influenciar as secreções gastrintestinais e a peristalse, acentuar as reaçōes por corticosteróides e modificar os níveis sangǘneos de creatinina e lipoproteínas. SVEDMYR ${ }^{14}$ ratifica essa afirmação acrescentando que "até mesmo pessoas saudáveis reclamam desses efeitos quando tomam algum placebo".

BEECHER $^{2}$ observou 35 diferentes efeitos tóxicos em pacientes em uso de placebos. Pagge, citado por COLEMAN ${ }^{5}$, anotou 38 tipos diferentes de efeitos colaterais. Os problemas mais comuns relatados por estes autores foram: sialos 
quese, náusea, opressāo, cefaléia, diticuldade de concentração, sonolência, distúrbios do sono, urticária, constipação, anorexia, vertigens e até mesmo colapso por reação anatilática. A esse tipo de efeito CARVALHO NETO4 denomina "efeito nocebo".

O uso de placebos, portanto, quando mal orientado, é potencialmente perigoso.

\section{6 - Indicaçōes e contra-indicaçōes do uso dos placebos}

Há uma grande evidência, atualmente, de que em uma grande variedade de sintomas a administração de uma substância inerte produz uma melhora acentuada.

BEECHER $^{2}$ afirma que 30 a $40 \%$ dos pacientes que sofrem algum desconforto respondem tão bem a uma injeçāo placebo, como o fariam a uma injeçāo de $10 \mathrm{mg}$ de morfina e que este percentual provavelmente aumentará quando o estresse estiver associado à dor. As principais razōes, por ele encontradas, que procuram justificar o uso do placebo são assim resumidas:

- Como um instrumento psicológico na terapia de certos sintomas derivados das doenças mentais.

- Como um recurso para o médico cansado de lidar com pacientes neuróticos.

- Em trabalhos experimentais em que se procura determinar o efeito verdadeiro de drogas, excluindo-se o fenômeno da sugestāo.

- Como um insurumento de importância no estudo dos mecanismos de ação das drogas.

Segundo CARVALHO $\mathrm{NETO}^{4}$, "polêmicas intermináveis têm ocorrido quanto ao aspecto ético de prescreverem-se placebos com finalidade terapêutica determinada". E, continua ponto de partida para a discussão a pergunta: "ciesde que posso aliviai a dor de meu paciente com $1 \mathrm{ml}$ de soro fisiológico, por que ministrar-Ine opiáceos?"

Os pacientes cronicamente queixosos desafiam a necessidade do médico de acreditar que ele pode curar "seu paciente". Prescrevendo o placebo ele tenta, muitas vezes, convencer a si mesmo que de fato, "curou o paciente" mas que ele está simplesmente "se recusando" a melhorar GOODWIN et aliii"

O maior risco do placebo é que, sendo adminstrado, o paciente poderá não receber o tratamento específico para sua doença quando tal tratamento está disponível. Por esta razāo, alguns autores fazem recomendaçōes quanto ao seu uso.

SVEDMYR 14 diz que "o placebo nunca deve ser usado terapeuticamente antes que um diagnóstico exato tenha sido formado". Além disso, "em doenças malignas o placebo não deve ser usado em lugar da medicaçāo altemativa, mesmo 
porque as chances de um efeito benéfico do tratamento são mínimas".

GOODWIN et aliii afirmam que:

- "A terapia placebo não deve ser ordenada antes que u médico tenha examinado suas indicações de forma até mesmo mais cuidadosa do que se estivesse para prescrever uma terapia especíticia.

- O médico que réíaxa seus esforços diagnósticos porque o paciente aparenta responder a um placebo, pode perder a oportunidade de tratar uma condição remediável.

- A solução é o médico usar um placebo apenas quando ele se sente seguro que é verdadeiramente necessário para o bem do paciente que ele assim o faça e tenha reconhecicio e considerado adequadamente quaisquer sentimentos interferentes qui jossam ter surgido dentro de si".

Para WALLACE"19, "ná suriictite uma indicação para o uso dos placebos: nos estudos duplo-cegos. Alén cisissu, o placebo como tratamento deve ser banido sempre".

\section{2 - IMPLICAÇÕES DO USO E EFEITO DO PLACEBO PARA O ENSINO E A ASSISTÊNCIA DE ENFERMAGEM.}

GOODWIN et alii ${ }^{7}$ realizaram uma pesquisa, envolvendo 60 médicos, 39 enfermeiras registradas e 27 enfermeiras práticas licenciadas e ajudantes-médicas de dois hospitais-escola universitários, para averiguar conhecimentos acerca do efeito placebo, bem como padrōes do uso do placebo. Segundo eles, o grupo de enfermeiras (RNs e LPNs) foi incluído por causa da impressão que tinha de que elas exerciam um papel influente na decisão do médico de prescrever placebos para os pacientes hospitalizados.

Esse estudo mostrou que muitos médicos e enfermeiras subestimavam, ou estavam mal informados sobre o poder do placebo em aliviar a dor. Além disso, poucos médicos e enfermeiras relataram alguma instrução formal sobre o efeito placebo e sua utilidade. Em conseqüência disso, os placebos estavam sendo usados, geralmente, em pacientes suspeitos de "fingimento", isto é, naqueles que solicitavam constantemente por analgésicos. Se o placebo resultava em alívio de dor, isto era tomado como prova de que o paciente estava abusando da atenção da equipe.

É necessário que nós paremos para refletir um pouco sobre o que esie cstucio pode significar.

Quantas destas "substâncias inofensivas" são administradas diariamente nas enfermarias hospitalares, para o paciente que se queixa persistentemente de dores ou que está somente "querendo" um comprimido? Por que as enfermeiras confiam

Rer: Esc. Enf. USP, Sāo Paulo, 23(2):83-93, abr. 1989 
nos placebos? São perguntas feitas por WALLACE ${ }^{19}$

ORLANDO ${ }^{11}$, discorrendo sobre os elementos do processo de enfermagem, nos diz que "a situaçāo de enfermagem compreende três elementos básicos: (1) o comportamento do paciente; (2) a reaçāo do enfermeiro e (3) as açōes de enfermagem que sao destinadas ao benefício do paciente".

Em relaçāo ao comportamento do paciente diz que ele pode ser percebido pelo enfermeiro através de expressões não-verìis e de expressōes verbais, que compreendem qualquer coisa que o paciente diz, mclusive: "posso tomar algo para minha dor?". O exemplo seguinte, que achamos por bem incluir neste trabalho, nos mostra "quāo sem importância e de nenhuma preocupaçāo profissional pode ser e parecer o comportamento apresentado pelo paciente até que seu significado para ele seja compreendido".

Uma paciente solicita codelna para dor.

12L1Uma paciente, espontaneamente disse à enfermeira que acabava de entrar no quarto: "Enfermeira, eu gostaria de tomar codeína para dor, agora". "Por que a senhora quer codeina?", perguntou a enfermeira. "Porque nāo me sinto bem". Enquanto a entermeira tentava saber o significado, para a paciente, da dor e do desconforto, a paciente disse: "Sinto como se estivesse com uma escoriaçāo na coxa, e simplesmente não posso suportar essa sensação pegajosa e essa coceira". Juntas, decidiram retirar algum esparadrapo antigo que estivesse junto do novo. Enquanto a enfermeira fazia isso a paciente disse: "Ah... agora me sinto muito bem". Quando a enfermeira terminou, um olhar de absoluto prazer tomou o rosto da paciente enquanto ela disse: "Nossa, como eu estou me sentindo bem! Tomei codeína duas vezes ontem à noite e não resolveu. Agora não preciso dela". ORLANDO $^{\prime \prime}$.

Durante o XXXII Congresso Brasileiro de Enfermagem, realizadóo em Brasília de 01 a 07 de junho de 1980, um dos temas oficiais foi "A enfermagem e a totalidade da Prática - Relaçāo de Ajuda”.

Para CARVALHO' 'a assistência de enfermagem, como resposta diretamente voltada para as necessidade dos clientes, configura-se como relaçäo de ajuda".

Segundo ANDRADE" "a enfermagem se correlaciona e quase se confunde com o relacionamento de ajuda e, só SE PODE IDENTIFICAR COMO UM AGENTE DE ENFERMAGEM a pessoa que, legalmente habilitada, evidencia em sua vida profissional e na integridade de sua própria existência, os comportamentos que delineiam o perfil e a personalidade de um agente de ajuda".

Ora, um pedido por "um comprimido" é certamente em "APELO POR AJUDA".

Segundo WALLACE ${ }^{19}$ o entermeiro que administra apenas um placebo nes- 
tas circunstâncias "acredita em conseguir paz a qualquer preço e não toma conhecimento do pedido de ajuda que considera injustificado". Diz ainda que os placebos são um abuso de confiança e contradizem tudo o que o enfermeiro aprendeu na escola. Ele estará, certamente, ganhando tempo. Mas para quê?

Ajudar o paciente a exteriorizar suas necessidades e sentimentos pode ser contesto, como muito bem nos disse HENDERSON", "como uma concepção romântica da enfermagem". Segundo ela, "quanto mais compreensiva for a enfermeira, tanto mais confiança terão nela o doente e sua familia e tanto melhor poderá ajudar o paciente a superar os efeitos psicologicos da doença”. E, ainda mais, "para determinar o estado do paciente, o médico tem confiado de certo modo nas informaçōes que os enfermeiros lhe apresentam".

Se o paciente se queixa constantemente de dores o obtém alívio após uma injeçāo de soluçāo fisiológica, o que isso pode significar? Para muitos, a resposta seria que o placebo permitiu distinguir que a dor do paciente era imaginária. Enuretanto, mesmo tendo um componente psiculógico, a dor o estava incomodando. Nāo poderia ser ela a exteriorização de sua ansiedade ou depressão relacionadas com o tato de estar hospitalizado? Por que, então, ao invés de se administrar seguidamente o placebo, que surtiu efeito em uma primeira aplicação, não se cria uma situaçāo interativa que permita ao paciente exteriorizar seus sentimentos e/ou temores?

A crescente especiaiização dos profissionais de saúde e a progressiva sofisticaçāo dos equipamentos por eles utilizados modificaram, de certa forma, a importância que o enfermeiro dá a determinadas atividades. Assim, administrar a medicaçāo aos pacientes tornou-se uma atividade simples, se comparada à complexidade das açōes exigidas pela atual tecnologia hospitalar. Entretanto, o momento da administraçāo de medicamentos foi, é, e continuará sendo uma oportunidade para o enfermeiro estabelecer o processo de relação de ajuda com o paciente pois, "o atender, responder, iniciar e orientar são os elementos interativos que permitem a operacionalização do processo" ANDRADE ${ }^{1}$.

\section{3 - CONCLUSŌES E SUGESTÕES}

Entendendo-se por mito algo que existe somente na imaginação das pessoas e que, por isso mesmo, pode influenciá-las, chega-se à conclusão de que muitos mitos foram criados em torno do placebo e do efeito placebo. Entre eles: que os placebos agem sobre a imaginação das pessoas e não sobre o físico; que os placebos podem não ajudar, mas não podem causar danos; que os placebos agem primariamente sobre pessoas sugestionáveis, e que o efeito placebo depende apenas do paciente, não do enfermeiro ou do médico.

O emprego do placebo não nos pareceu, pelo estudo realizado, um assunto desprovido de importância. Ao contrário, além do risco potencial de o paciente 
apresentar efeitos tóxicos após seu uso, corre-se também o risco de perder a confiança do paciente e de fazê-lo acreditar, no caso dos sintomas de ordem psicogênica, que sua doença realmente existia, já que os sintomas regrediram após a administração do medicamento prescrito pelo médico, deixando-se de tratar a causa básica para sua exteriorização.

Aparentemente, tem se dado pouca importância, durante a formação do médico e do enfermeiro, ao estudo do efeito placebo. Os próprios livros de Farmacologia nāo dão assunto a ênfase devida, haja vista a dificuldade que tivemos para fazer a revisāo de literatura existente sobre o placebo, tendo que recorrer principalmente a periódicos estrangeiros. Essa deficiência se acentua no tocante aos aspectos específicos de enfermagem.

Esperamos ter contribuído para a correção de alguns erros conceituais soure o efeito placebo e, para finalizar, sugerimos:

- que as escolas de Enfermagem incluam o estudo do efeito placebo como tópico obrigatório dos programas de Farmacologia;

- que os enfermeiros contribuam para um melhor entendimento sobre o efeito placebo, evitando usá-lo para determinar se a dor do paciente é real ou imaginária, para determinar a severidade da dor, ou para julgar a personalidade do paciente, sugestibilidade ou psicopatologia;

- que se atentem para os aspectos éticos do emprego do placebo, tirando-se proveito das recomendaçöes cautelosas feitas pelos autores que têm se dedicado ao estudo do assunto.

MERIGHil, M. A. B.; OLLITA, I.; GARCIA, T. R. Placebo effect: implications for teaching and nursing practice. Rev. Esc. Enf. USP, Săo Paulo 23(2):-, Aug. 1989.

The authors makes shows a bibliography review on the placebo and its effect, focusing on its conceptualization, description, types, action, indications and characteristics of the effects for teaching and nursing practice.

UNITERMS: Nursing cure. Placebas.

\section{BIBLIOGRAFIA}

1. ANDRADE, M. D. L. de. A enfermagem e a religiåo de ajuda. In: CONGRESSO BRASILEIRO DE ENFERMAGEM, 32, Brastlia, 1980. Anais. Brasıla, Associaç̧o Brasileir de Enfermagem, 1980. p. 81-4.

2. BEECHER, H. K. The powerfull placebo. J. Amer. Med. Art., Chicago, 15 (17):1602, Dec. 1955.

3. CARVALHO, V. de. A relaçăo de ajuda e a totalidade da pratica de enfermagem. In: CONGRESSO BRASILEIRO DE ENFERMAGEM, 32, Brasflia, 1980. Anais. Brasılia, Associaç5o Brasileira de Enfermagem, 1980. p. 66-72. 
4. CARVAlho NETO, E. Farmacologia Clínica. In: ZANINI, Antonio Carlos \& OGA, Seizi. Farmacologia aplicada. 2 ed. Såo Paulo, Atheneu, 1982. cap. 7, p. 76-7.

5. COLEMAN, V. On placebos. Nurs. Mirror, Sussex, 139(13):79, Sept. 1974.

6. COUTINHO, A. C. Dicionário Encicloptdico de medicina. 3 ed. Rio de Janeiro, Argo, 1977, v.2, p. 1842.

7. GOODWIN, J. et alii. Knowledge and use of placebos by house officers and nurses. Ann. Intern. Med., Philadelphia, 91(1):106-110, 1979.

8. GOSHEN, C. E. The placebo effect - for who? Amer. J. Nurs. New York, 66(2):293-4, Feb. 1966.

9. HENDERSON, V. Princípios básicos sobre cuidado de enfermagem. Rio de Janeiro, Associação Brasileira de Enfermagem, 1962. 62 p.

10. LOWINGER, P. \& DOBIE, S. What makes the placebo work? Arch. Gen. Psychiatry, Chicago, 20:84-8, Jan, 1969.

11. ORLANDO, I. J. O relacionamento dinnámico enfermeiro/paciente. São Paulo, EPU, 1978. p.44-9.

12. PERRY, S. W. J. \& HEIDRICH, G. Placebo response: wyth and matter. Amer. J, Nurs.,New York, 81(4):720-5. Apr. 1981.

13. SHAPIRO, A. K. The placebo effect in the history of medical tretment: implications for psychiatry. Amer. J. Psychiatry, Washington, 116(4):298-304, Oct. 1959.

14. SVEDMYR, N. The placebo effect. Scand. J. Rehabil. Med. Stockholm, 11:169-172, 1978.

15. TROUNCE, J. R. Farmacologia para enfermagem. 7 ed. Rio de Janeiro, Guanabara Koogan, 1977. p. 305-6.

16. VELASQUEZ, B. L. Terapética con sus fundamentos de farmacología experimental. Barcelona, Cientifico-Médica, 1958. p. 46-7.

17. VOGEL, A. V. et alii. The therapeutics of placebo. Aust. Fam. Phisician, Sidney, 22(1):105-9, July 1980.

18. WALIKE, B. C. \& MEYER, B. Relation between placebo reactivity and selected personality factors. Nurs. Res., New York, 15(2):119-23, Spring 1966.

19. WAllaCE, C. M. Placebos. Nurs. Mirror, 128(11):26, Sussex, Apr 1969.

20. ZANINI, A. C. et alii. Influência medica na açăo de drogas: efeito placebo. Rev. Assoc. Med. Bras., Sâo Paulo, 22(1):35-6, jan. 1976.

21. —— OGA, S. Farmacologia aplicada. 2 ed. Såo Paulo. Atheneu, 1982. p. 5-12.

Rocebido para publicaçāo em 28/06/88. 